Fetal Diagnosis

and Therapy
Fetal Diagn Ther 2008;23:258-262

DOI: $10.1159 / 000123611$
Received: August 31, 2006

Accepted after revision: January 5, 2007

Published online: April 14, 2008

\title{
Liver Position Is a Prenatal Predictive Factor of Prosthetic Repair in Congenital Diaphragmatic Hernia
}

\author{
Shaun M. Kunisaki ${ }^{a, b}$ Carol E. Barnewolt ${ }^{b, c}$ Judy A. Estroff ${ }^{b, c}$ \\ Luanne P. Nemes $^{a, b}$ Russell W. Jennings ${ }^{a, b}$ Jay M. Wilson ${ }^{a, b}$ Dario O. Fauza ${ }^{a, b}$ \\ ${ }^{a}$ Department of Surgery, ${ }^{\mathrm{b}}$ Advanced Fetal Care Center, and ' ${ }^{\mathrm{C}}$ Department of Radiology, Children's Hospital Boston \\ and Harvard Medical School, Boston, Mass., USA
}

\section{Key Words}

Congenital diaphragmatic hernia, prenatal diagnosis ·

Cell therapy $\cdot$ Tissue engineering

\begin{abstract}
Objective: To determine whether any common maternalfetal variable has prenatal predictive value of prosthetic repair in congenital diaphragmatic hernia. Methods: This was a 5-year single-center retrospective review of fetal congenital diaphragmatic hernia referrals. Multiple prenatal variables were correlated with the need for a prosthetic repair. Statistical analyses were by Fisher's exact and Mann-Whitney U-tests, as appropriate $(\mathrm{p}<0.05)$. Results: Fetal liver position was a predictor of prosthetic repair. The presence or absence of liver herniation was correlated with prosthetic repair rates of 83.3 and $23.1 \%$, respectively ( $p<0.001$ ). All patients with moderate/severe liver herniation required a prosthetic patch. Conclusion: Liver herniation has prenatal predictive value for the need for prosthetic repair in congenital diaphragmatic hernia. This finding should be valuable during prenatal counseling for clinical trials of engineered diaphragmatic repair.

Copyright $\odot 2008$ S. Karger AG, Basel
\end{abstract}

\section{Introduction}

According to the Congenital Diaphragmatic Hernia $(\mathrm{CDH})$ Study Group, $51 \%$ of $\mathrm{CDH}$ patients have a diaphragmatic defect that cannot be closed primarily [1]. In such circumstances, diaphragmatic reconstruction using an acellular prosthesis, such as expanded polytetrafluoroethylene, is considered the standard of care. Unfortunately, acellular prostheses are known to be unreliable in the mid to long term in $\mathrm{CDH}$ survivors. Multiple large series have shown that up to approximately $40 \%$ of all prosthetic repairs eventually detach from the native diaphragm within the first few years of life [2-5]. Prosthetic patch repair has also been associated with other serious morbidities, including infection, chest wall and spinal column deformities, small bowel obstruction and restrictive lung disease [4].

We have previously shown, experimentally, that diaphragmatic reconstruction with autologous engineered tissue is a viable and potentially improved alternative for diaphragmatic replacement in the neonatal period [6-8]. We have also determined that the amniotic fluid is the preferred cell source for the engineering of a diaphragmatic patch [8-10]. Translated clinically, from a routine diagnostic amniocentesis, an autologous diaphragmatic tendon would be built from the mesenchymal cells normally found in the amniotic fluid, in parallel to gestation,

Dario O. Fauza, MD

Children's Hospital Boston

300 Longwood Ave, Fegan 3

Boston, MA 02115 (USA)

Tel. +1 617919 2966, Fax +1 617730 0910, E-Mail dario.fauza@childrens.harvard.edu 
Fig. 1. $T_{2}$-weighted, coronal magnetic resonance images of left-sided fetal CDHs in patients with no herniation (a), mild herniation (b) and severe herniation (c) of the liver into the thoracic cavity. The arrows and asterisks denote the left hemidiaphragm and intrathoracic liver, respectively.
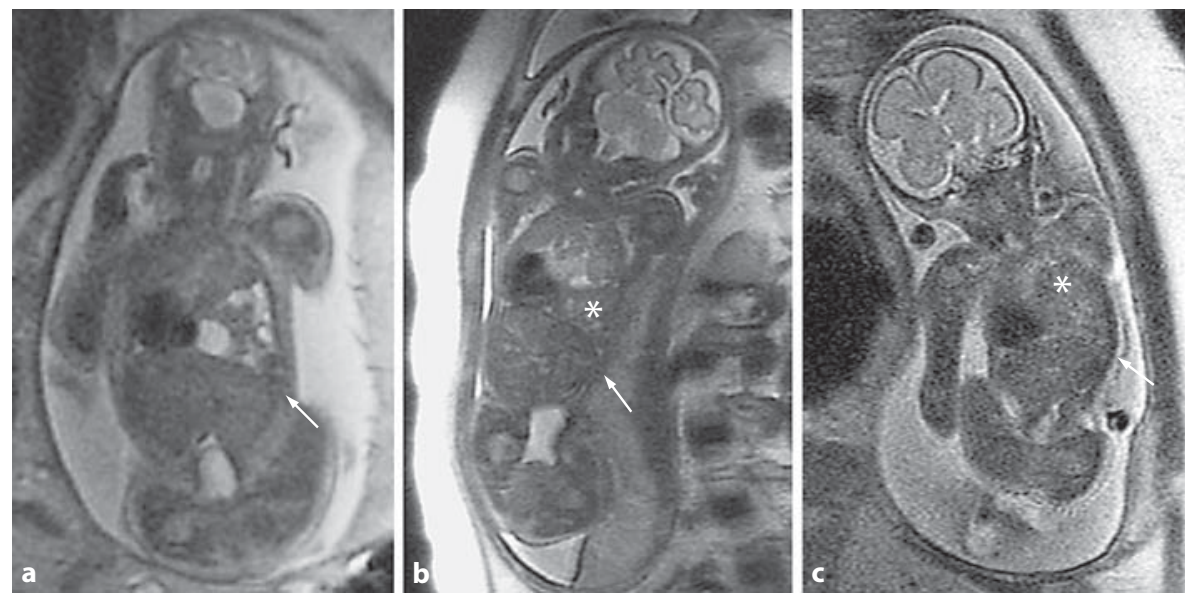

so that it could be readily available for surgical reconstruction at birth.

Given the need for the engineering of fetal tissue during pregnancy, clinical application of this concept would benefit from the prenatal identification of infants with a high likelihood of requiring a prosthetic repair, which had yet to be reported in the literature [11]. Therefore, the purpose of this study was to determine whether prenatal markers for prosthetic diaphragmatic repair could be defined among common clinical, anatomical and imaging maternal-fetal variables.

\section{Materials and Methods}

Institutional Review Board approval (protocol M02-10-240) was obtained for a retrospective review of all prenatally diagnosed $\mathrm{CDH}$ patients referred to the Children's Hospital Boston. From October 2000 to August 2005, 90 consecutive patients were evaluated at our Advanced Fetal Care Center. The maternal-fetal variables studied included fetal gender, gestational age at diagnosis of $\mathrm{CDH}$, side of the hernia and detailed ultrasonography with colorflow Doppler (ATL 5000, Philips, Bothell, Wash. or Sequoia, Siemens, Mountain View, Calif., USA). In most patients evaluated during the second trimester, the lung-to-head ratio (LHR) was also prospectively calculated using methods as previously described [12]. In the majority of cases, further characterization of the diaphragmatic hernia was performed with magnetic resonance (MR) imaging, using a 1.5-T system (TwinSpeed; GE, Waukesha, Wisc., USA) equipped with various coils as appropriate for maternal body habitus. Multiple single-shot, fast-spin echo $\mathrm{T}_{2}$-weighted and fast technique $\mathrm{T}_{1}$-weighted images were obtained in the sagittal, axial and coronal planes. For all left-sided hernias, the degree of intrathoracic liver (i.e. none, mild or moderate/severe; fig. 1) was prospectively assessed by MR. Mild liver herniation was defined as less than the entire left lobe present within the thoracic cavity. Moderate/severe liver herniation was defined as the entire left lobe or more present therein. The presence of associated cardiac anom- alies was assessed by echocardiography in all fetuses. After the initial evaluation, expectant mothers received routine, nondirective counseling by our multidisciplinary team.

Neonates underwent elective hernia repair by 1 of 8 staff pediatric surgeons, with standard perioperative care based on minimal barotrauma, permissive hypercapnea and, if necessary, early use of extracorporeal membrane oxygenation (ECMO), as previously described $[13,14]$. Primary closure was the preferred method of repair of the hernia. However, when the defect could not be closed primarily without undue tension, an expanded polytetrafluoroethylene patch was employed. Defect size was not routinely measured by the different operating surgeons.

Statistical correlations between prenatal variables and patch utilization were calculated by Fisher's exact and Mann-Whitney U-tests, as appropriate for categorical and continuous variables, respectively, using commercially available software (Instat, San Diego, Calif., USA). p values of less than 0.05 were considered significant.

\section{Results}

Of the $90 \mathrm{CDH}$ fetuses referred during the 5 -year period, complete follow-up data was available on 59 (65.6\%) liveborn patients, all of whom had been delivered locally and subsequently transferred to our institution for surgical repair and further management. Five (8.4\%) of these neonates had known chromosomal abnormalities and/or were born before 31 weeks' gestation, resulting in death prior to diaphragmatic repair. The recorded prenatal characteristics for the remaining 54 patients, all of which underwent diaphragmatic repair at our hospital, are summarized in table 1 . The mean gestational age at delivery was 37.8 weeks (range 32.0-43.0 weeks). Five patients had ventricular septal defects diagnosed prenatally. There were no karyotype abnormalities detected in this group, except for 1 patient who had mosaicism for isochromo- 


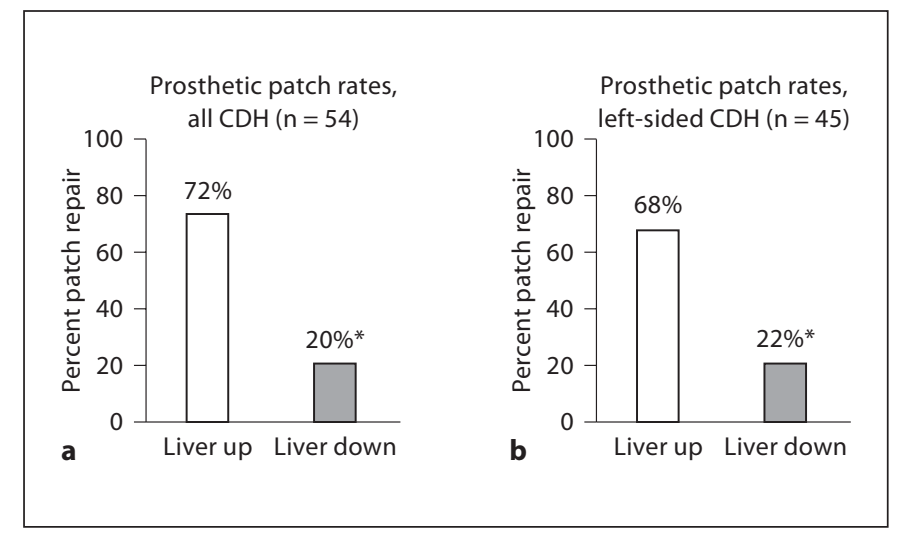

Fig. 2. Rates of prosthetic patch repair of $\mathrm{CDH}$ according to the presence ('Liver up') or absence ('Liver down') of variable degrees of liver herniation into the thorax, as identified on prenatal imaging: a all $\mathrm{CDH}$ patients, $\mathbf{b}$ left-sided $\mathrm{CDH}$ only. Liver herniation into the thoracic cavity was significantly associated with use of a prosthetic patch $\left({ }^{*} \mathrm{p}<0.01\right)$.

Table 1. Summary of prenatal variables

\begin{tabular}{llr}
\hline & Number & $\%$ \\
\hline Gender & & \\
$\quad$ Male & 31 & 57.4 \\
$\quad$ Female & 23 & 42.6 \\
Defect location & & \\
$\quad$ Left & 44 & 81.5 \\
$\quad$ Right & 10 & 18.5 \\
Gestational age at diagnosis (weeks) & $23.6 \pm 6.6$ & \\
LHR (n = 28) & $1.28 \pm 0.42$ & \\
Liver herniation & 28 & 51.9 \\
Cardiac anomaly & 5 & 9.3 \\
\hline
\end{tabular}

$\mathrm{n}=54$ unless otherwise indicated. Data for gestational age at diagnosis and LHR are expressed as mean \pm SD.

Table 2. Relationship between degree of liver herniation and rates of patch repair in left-sided hernias $(n=44)$

\begin{tabular}{lcc}
\hline Degree of liver herniation & Number & \% patch \\
\hline None & 24 & 21.7 \\
Mild & 13 & 46.2 \\
Moderate to severe & 6 & $100^{*}$ \\
\hline
\end{tabular}

\% Patch denotes the percentage of prosthetic repairs.

* Denotes statistical significance compared to the other subgroups. some $12 \mathrm{p}$, consistent with Pallister-Killian syndrome. One fetus underwent tracheal occlusion at 26 weeks' gestation and was delivered prematurely, at 32 weeks.

The mean age at diaphragmatic repair was 2.4 days after birth (range 0-14 days). All prenatally identified cases of liver herniation were confirmed intraoperatively; there were no false-negatives in this series. An expanded polytetrafluoroethylene patch was employed in $26(48.1 \%)$ of the 54 neonates. Eighteen (33.3\%) repairs were performed on ECMO. Survival rates after primary and patch diaphragmatic repair were 100 and $69.2 \%$, respectively.

The position of the fetal liver was a significant predictor of the need for prosthetic repair. The presence or absence of liver herniation was correlated with prosthetic repair rates of 83.3 and $23.1 \%$, respectively (fig. $2 \mathrm{a} ; \mathrm{p}<0.01$ ). The specificity and sensitivity of liver herniation as a prenatal marker for prosthetic repair were 76.9 and $71.4 \%$, respectively. The relative risk of prosthetic patch repair in the presence of liver herniation was 3.1 (95\% CI 1.5-6.5). In like manner, if only left-sided hernias were considered, the presence or absence of an intrathoracic portion of the liver was correlated with prosthetic repair rates of 65.0 and $25.0 \%$, respectively (fig. $2 \mathrm{~b} ; \mathrm{p}<0.05$ ). Among left-sided hernias, the relative risk of prosthetic patch repair in the presence of liver herniation was 2.6 (95\% CI 1.2-5.6). The specificity and sensitivity of liver herniation as a prenatal marker for prosthetic repair of left hernias were 75 and $71 \%$, respectively. The analysis of left-sided defects by the degree of liver herniation showed that 46.2 of mild and $100 \%$ of moderate/severe cases required a prosthetic patch (table 2; $\mathrm{p}<0.05$ between the groups). The identification of an intact diaphragm on sagittal imaging did not exclude the presence of a large hernia defect.

The antenatal detection of a structural cardiac anomaly was the only other prenatal variable studied that was associated with the prosthetic patch repair rate (table 3; $p=0.02$ ). Neither the side of the hernia nor the LHR were found to be predictive of prosthetic repair $(p=0.29$ and 0.10 , respectively). Although the mean gestational age at diagnosis was lower before prosthetic patch repair compared with primary repair $(21.9 \pm 5.3$ and $25.2 \pm 7.4$ weeks, respectively), this difference did not reach statistical significance $(\mathrm{p}=0.14)$.

\section{Discussion}

The survival rates of infants with severe $\mathrm{CDH}$ have increased dramatically, particularly over the past two decades $[1,15]$. As a result, recurrent diaphragmatic hernia, 
Table 3. Univariate analysis of prenatal variables on rates of prosthetic patch repair

\begin{tabular}{lccr}
\hline Variable & \multicolumn{2}{c}{ Type of repair } & \multirow{2}{*}{ p value } \\
\cline { 2 - 3 } & primary $(\mathrm{n}=28)$ & patch $(\mathrm{n}=26)$ & \\
\hline Female gender, $\mathrm{n}$ & $11(39 \%)$ & $12(46 \%)$ & 0.784 \\
Gestational age at diagnosis (weeks) & $25.2 \pm 7.4$ & $21.9 \pm 5.3$ & 0.140 \\
LHR & $1.42 \pm 0.38$ & $1.18 \pm 0.44$ & 0.102 \\
Liver herniation, $\mathrm{n}$ & $8(28.6 \%)$ & $20(76.9 \%)$ & $<0.001^{*}$ \\
Cardiac anomaly, $\mathrm{n}$ & $0(0 \%)$ & $5(19.2 \%)$ & $0.021^{*}$ \\
\hline
\end{tabular}

Data for gestational age and LHR are expressed as mean \pm SD.

* Denotes statistical significance $(\mathrm{p}<0.05)$. a previously underappreciated morbidity, is now being recognized with increasing frequency in long-term survivors [2-5]. In a recently published series, $41 \%$ of children who underwent prosthetic diaphragmatic patch repair later required one or more operations for repair of a re-herniation [3]. Even higher recurrence rates have been associated with repair of the defect on ECMO $[3,16]$. Despite these unacceptably high recurrence rates, acellular prostheses continue to be implanted widely, because of their simplicity, short-term efficacy and minimal physiologic demands on critically ill neonates when compared with the alternative of using an autologous muscle flap fashioned from the abdominal wall.

The ideal diaphragmatic substitute should require minimal dissection, result in minimal to no herniation/ eventration, and allow for normal growth of the chest wall [17]. To date, an engineered diaphragmatic construct composed of autologous living cells remains the only biomaterial that could potentially meet these requirements, as well as remodel and grow itself. Since our initial description of engineered diaphragmatic repair in sheep [6], subsequent studies from our group utilizing different cell sources and various biodegradable scaffolds have demonstrated superior mechanical and functional outcomes with mesenchymal amniocyte-based engineered constructs when compared with equivalent muscle-based and acellular grafts $[7,8]$. The amniotic fluid is also an ideal cell source in this setting because the mesenchymal cells required for engineering a diaphragmatic construct are readily abundant therein, easy to isolate from a routine diagnostic amniocentesis, thereby posing no added morbidity risk to the maternal-fetal unit, and proliferate quickly ex vivo in parallel with the remainder of gestation [9]. In the United States and many developed countries, an amniocentesis is routinely indicated whenever a $\mathrm{CDH}$ is diagnosed by fetal imaging, regardless of whether there is liver herniation or not. However, given the logistical implications of a clinical trial of engineered diaphragmatic repair, translation of this novel therapeutic concept would benefit from identifying fetuses that would be more likely to require a patch, given that approximately half of the infants with $\mathrm{CDH}$ can have their defects closed primarily.

Although experimental work in the nitrofen rat model has suggested a relationship between intrathoracic liver volume and size of the hernia defect [18], prior to the current study no one had reported/described any prenatal predictor of prosthetic repair in $\mathrm{CDH}$. In this study of 54 fetal CDH patients followed postnatally, liver position assessed on prenatal imaging was found to correlate with the need for a diaphragmatic prosthesis. Patch repairs were about 3 times more likely if there was any degree of fetal liver herniation into the thoracic cavity. The diagnosis of liver herniation on fetal imaging had an overall positive and negative predictive value of 71.4 and $76.9 \%$, respectively. Furthermore, the degree of liver herniation, as assessed prospectively by MR, was found to be predictive of prosthetic patch repair. Whereas less than one half of the patients with mild herniation underwent patch repair, all cases of moderate/severe liver herniation required a patch. The difference between these two liver herniation subgroups was statistically significant.

Two additional variables previously considered by some to be of prognostic value in predicting the severity of lung hypoplasia in $\mathrm{CDH}$, namely the gestational age at diagnosis and the LHR $[12,19,20]$, were not found to be predictive of patch repair in our series. Although many now refute the prognostic value of the gestational age at diagnosis and the LHR, a lack of correlation between prognostic markers and markers for prosthetic repair should not come as a surprise, in that it has long been accepted that there is no relationship between the size of the diaphragmatic opening and the volume of the herniation. 
The present data have limitations. The overall positive and negative predictive values of fetal liver herniation of 71.4 and $76.9 \%$, respectively, mean that a sizeable fraction of fetuses without liver herniation will still require prosthetic repair, and vice versa. One must also be careful in interpreting fetal liver herniation per se as a reliable marker of actual defect size, since liver herniation has been associated with an increased severity of lung hypoplasia [21]. Thus one could speculate that a possibly more frequent use of perioperative ECMO in patients with liver herniation could also contribute to the higher frequency of patch repairs in these infants, given the risks for bleeding complications associated with aggressive dissection of the diaphragmatic rim in the setting of continued anticoagulation. Likewise, the fact that ECMO was used in all 5 of our $\mathrm{CDH}$ neonates with associated cardiac anomalies may have contributed to the use of patches in these patients. In addition, in many cases, the decision to use prosthesis depends, to a certain extent, on a somewhat subjective choice by the surgeon. The fact that
8 surgeons performed the repair in this series should have minimized the impact of this variable in our data, though. Prospective measurement of the actual size of the hernia defect intraoperatively should enable us to better elucidate this confounding issue in the future.

Despite the aforementioned caveats, this study suggests that fetal liver position can be a practical criterion for identifying fetuses/infants most likely to benefit from engineered diaphragmatic reconstruction in the treatment of $\mathrm{CDH}$. Taken more broadly, these findings should also be of use in prenatal counseling, given the known association between prosthetic patch repairs and longterm morbidities other than hernia recurrence, including gastroesophageal reflux disease [22].

\section{Acknowledgments}

S.M.K. was supported by grants from the NIH National Research Service Award DK065406-02 and the V.H. Kazanjian Surgical Research Fellowship of the Massachusetts General Hospital.

\section{References}

1 Clark RH, Hardin WD Jr, Hirschl RB, Jaksic T, Lally KP, Langham MR Jr, Wilson JM: Current surgical management of congenital diaphragmatic hernia: a report from the Congenital Diaphragmatic Hernia Study Group. J Pediatr Surg 1998;33:1004-1009.

-2 Hajer GF, vd Staak FH, de Haan AF, Festen C: Recurrent congenital diaphragmatic hernia: which factors are involved? Eur J Pediatr Surg 1998;8:329-333.

3 Moss RL, Chen CM, Harrison MR: Prosthetic patch durability in congenital diaphragmatic hernia: a long-term follow-up study. J Pediatr Surg 2001;36:152-154.

4 Rowe DH, Stolar CJ: Recurrent diaphragmatic hernia. Semin Pediatr Surg 2003;12: 107-109.

5 Grethel EJ, Cortes RA, Wagner AJ, Clifton MS, Lee H, Farmer DL, Harrison MR, Keller RL, Nobuhara KK: Prosthetic patches for congenital diaphragmatic hernia repair: Surgisis vs. Gore-Tex. J Pediatr Surg 2006;41: 29-33.

-6 Fauza DO, Marler JJ, Koka R, Forse RA, Mayer JE, Vacanti JP: Fetal tissue engineering: diaphragmatic replacement. J Pediatr Surg 2001;36:146-151.

-7 Fuchs JR, Kaviani A, Oh JT, LaVan D, Udagawa T, Jennings RW, Wilson JM, Fauza DO: Diaphragmatic reconstruction with autologous tendon engineered from mesenchymal amniocytes. J Pediatr Surg 2004;39:834-838

${ }_{8}$ Kunisaki SM, Fuchs JR, Kaviani A, Oh JT, LaVan DA, Vacanti JP, Wilson JM, Fauza DO: Diaphragmatic repair through fetal tis- sue engineering: a comparison between mesenchymal amniocyte- and myoblast-based constructs. J Pediatr Surg 2006;41:34-39.

-9 Kaviani A, Perry TE, Dzakovic A, Jennings RW, Ziegler MM, Fauza DO: The amniotic fluid as a source of cells for fetal tissue engineering. J Pediatr Surg 2001;36:1662-1665.

10 Kaviani A, Guleserian K, Perry TE, Jennings RW, Ziegler MM, Fauza DO: Fetal tissue engineering from amniotic fluid. J Am Coll Surg 2003;196:592-597.

11 Graham G, Devine PC: Antenatal diagnosis of congenital diaphragmatic hernia. Semin Perinatol 2005;29:69-76.

12 Metkus AP, Filly RA, Stringer MD, Harrison MR, Adzick NS: Sonographic predictors of survival in fetal diaphragmatic hernia. J Pediatr Surg 1996;31:148-151; discussion 151152.

13 Lally KP, Paranka MS, Roden J, Georgeson KE, Wilson JM, Lillehei CW, Breaux CW Jr, Poon M, Clark RH, Atkinson JB: Congenital diaphragmatic hernia. Stabilization and repair on ECMO. Ann Surg 1992;216:569-573.

14 Muratore CS, Kharasch V, Lund DP, Sheils C, Friedman S, Brown C, Utter S, Jaksic T, Wilson JM: Pulmonary morbidity in 100 survivors of congenital diaphragmatic hernia monitored in a multidisciplinary clinic. J Pediatr Surg 2001;36:133-140.

15 Downard CD, Jaksic T, Garza JJ, Dzakovic A, Nemes L, Jennings RW, Wilson JM: Analysis of an improved survival rate for congenital diaphragmatic hernia. J Pediatr Surg 2003. 38:729-732.
16 Atkinson JB, Poon MW: ECMO and the management of congenital diaphragmatic hernia with large diaphragmatic defects requiring a prosthetic patch. J Pediatr Surg 1992;27:754-756.

17 Lally KP, Cheu HW, Vazquez WD: Prosthetic diaphragm reconstruction in the growing animal. J Pediatr Surg 1993;28:45-47.

18 Langwieler T, Fiegel HC, Alaamian M, Mann O, Beshir I, Izbicki JR, Kluth D: The relationship of diaphragmatic defect, liver growth, and lung hypoplasia in nitrofen-induced congenital diaphragmatic hernia in the rat. Pediatr Surg Int 2004;20:509-514.

19 AdzickNS, VacantiJP, Lillehei CW, O’Rourke PP, Crone RK, Wilson JM: Fetal diaphragmatic hernia: ultrasound diagnosis and clinical outcome in 38 cases. J Pediatr Surg 1989; 24:654-657; discussion 657-658.

20 Bronshitein M, Lewit N, Sujov PO, Makhoul IR, Blazer S: Prenatal diagnosis of congenital diaphragmatic hernia: timing of visceral herniation and outcome. Prenat Diagn 1995; 15:695-698.

21 Albanese CT, Lopoo J, Goldstein RB, Filly RA, Feldstein VA, Calen PW, Jennings RW, Farrell JA, Harrison MR: Fetal liver position and perinatal outcome for congenital diaphragmatic hernia. Prenat Diagn 1998; 18: 1138-1142.

22 Muratore CS, Utter S, Jaksic T, Lund DP, Wilson JM: Nutritional morbidity in survivors of congenital diaphragmatic hernia. J Pediatr Surg 2001;36:1171-1176. 